\title{
Investigations on Efficiently Interfaced Steel Concrete Composite Deck Slabs
}

\author{
K. N. Lakshmikandhan, ${ }^{1}$ P. Sivakumar, ${ }^{1}$ R. Ravichandran, ${ }^{1}$ and S. Arul Jayachandran ${ }^{2}$ \\ ${ }^{1}$ Structural Engineering Research Centre, Council for Scientific and Industrial Research, Taramani, Chennai 600113, India \\ ${ }^{2}$ Indian Institute of Technology, Chennai 600036, India \\ Correspondence should be addressed to K. N. Lakshmikandhan; laknam553@yahoo.com
}

Received 19 February 2013; Revised 5 June 2013; Accepted 24 June 2013

Academic Editor: Francis Collombet

Copyright (c) 2013 K. N. Lakshmikandhan et al. This is an open access article distributed under the Creative Commons Attribution License, which permits unrestricted use, distribution, and reproduction in any medium, provided the original work is properly cited.

\begin{abstract}
The strength of the composite deck slab depends mainly on the longitudinal shear transfer mechanism at the interface between steel and concrete. The bond strength developed by the cement paste is weak and causes premature failure of composite deck slab. This deficiency is effectively overcame by a shear transferring mechanism in the form of mechanical interlock through indentations, embossments, or fastening studs. Development of embossment patterns requires an advanced technology which makes the deck profile expensive. Fastening studs by welding weakens the joint strength and also escalates the cost. The present investigation is attempted to arrive at a better, simple interface mechanism. Three types of mechanical connector schemes are identified and investigated experimentally. All of the three shear connector schemes exhibited full shear interaction with negligible slip. The strength and stiffness of the composite slabs with shear connectors are superior about one and half time compared to these of the conventional reinforced concrete slabs and about twice compared to these of composite slabs without mechanical shear connectors. The scheme 2 and scheme 3 shear connector mechanisms integrate deck webs and improve strength and stiffness of the deck, which can effectively reduce the cost of formworks and supports efficiently.
\end{abstract}

\section{Introduction}

Cold formed profiled steel sheets with embossments are widely used for composite floor decking systems in multistoried steel buildings wherein they remain permanently placed as an integral part of the floor system. The metal sheet performs as the formwork for concreting and as the primary tension reinforcement. The composite deck flooring results in faster construction and lighter floors. It also performs as a good ceiling surface and a convenient ducting for routing. Additional steel in the form of reinforcing bars or welded wire fabric needs to be provided for taking care of shrinkage, temperature, and the negative bending moment at supports. In composite slabs, the composite action between two dissimilar materials like concrete and steel is developed by bonding at the interface of two materials. The cement paste develops weak surface bonding and it is not sufficient to retain the composite behaviour. In addition surface bonding between concrete and metal deck requires shear connectors at the interface of the two materials. These shear connectors are normally the embossments in the deck sheets. These embossments are in typical pattern unique to each profile. These embossments develop friction as well as mechanical interlock between the concrete and steel deck. These embossment patterns carry the longitudinal shear developed at the interface of the concrete and steel sheet. The interlock prevents slip thereby enabling the two materials to act as a single entity of composite deck. The mechanical interlock can also be achieved by the use of welded stud connectors, and other local means of connection are in practice to develop the interfacial shear resistance.

The mechanical interlocking system in the deck profile provides the resistance to vertical separation and horizontal slippage between steel and concrete. From the numerous 


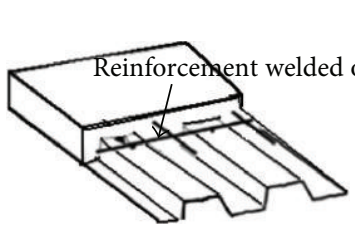

(a) Trapezoidal deck

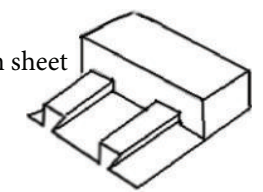

(b) Reentrant type
Figures (a) to (d) from Marimuthu et al. (2007)

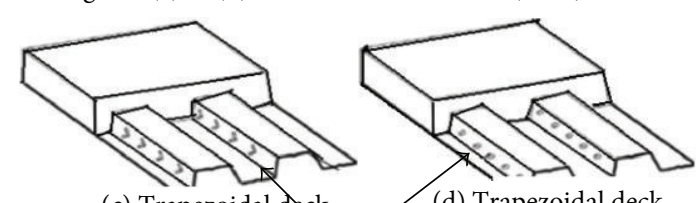

(c) Trapezoidal deck (d) Trapezoidal deck

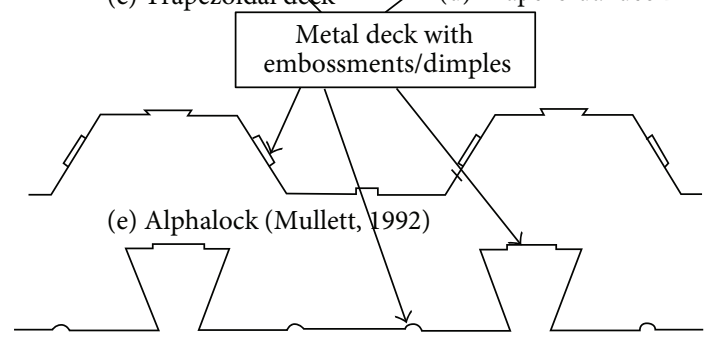

(f) Super Holorib (Mullett, 1992)

Figure 1: Transverse shear transferring mechanism (see $[1,2]$ ).

shear transferring mechanisms, few methods to provide transverse shear strength in composite steel deck slab are shown in Figure 1.

\section{Review of Literature}

Profiled steel sheets are widely accepted in recent times for fast track construction. It has been established as a pragmatic solution for the construction of tall steel buildings at minimum duration. The overall weight of structure is considerably reduced by these composite deck floors. The strength of the composite slab mainly depends on the interface bond between the steel and concrete. The steel deck and concrete are then essentially free from slip relative to one another and this resistance is provided by mechanical interlock, normally by embossments. As an alternative to these embossment patterns, the interface strength was enhanced by welding shear studs, rods, and wires on the metal decking top flange surface. The interface shear behaviour of composite deck slab is a complex phenomenon and several research works were carried out in the past four decades. In early 1976, Porter et al. [3] carried out a large number of experimental investigations on the composite deck slabs. The full-scale cold formed steel deck one-way composite floor slabs are tested to failure and established shear-bond failure mechanism. The shear-bond failure is defined as the formation of a diagonal tension crack in the concrete which results in slippage between the concrete and deck which is observed at the end of the span. Further, Porter and Ekberg [4] have conducted experimental studies on the shear-bond failure characteristics of one-way composite slabs and reported several observations on the significant parameters which are influencing the composite behaviour. They also recommended the design equations for the shear-bond capacity which is derived from the data collected from a series of performance tests on the slabs and establishing the linear regression relationship. This performance testing involves a series of tests which need more time and cost. In view of this, Seleim and Schuster [5] came with a solution to reduce the number of tests for the performance testing. From the experimental work carried out on composite deck slabs, they developed an ultimate shear-bond equation for composite deck slabs, in which the equation considered steel deck thickness as an important parameter. The number of laboratory tests required for earlier shear-bond equations decreased by about 75 percent. Seleim and Schuster concluded that neither the reinforcement ratio nor the compressive strength of concrete has a significant influence on the shear-bond resistance, but deck thickness was a governing parameter.

Calixto et al. [6] and Tenhovuori and Leskela [7] carried out an experimental investigation on one-way single span composite slabs with ribbed decking. Several aspects were studied including different steel deck thickness, total slab height, and the shear span length. The effect of stud bolt type connectors on the end anchorage was also investigated and found to have better performance of the composite slab. Chen [8] presented the test results of simply supportedsingle span composite slabs and two continuous composite slabs using different end restraints. The slabs with end anchorage with steel studs carry higher load due to higher shear-bond strength. The authors found that the shear-bond slip at the sheet-concrete interface governs the shear-bond failure of composite slabs rather than the strength of the end constraints. Marimuthu et al. [1] investigated their indigenous embossment pattern. They carried out experimental work on 18 slabs to get the shear-bond strength.

The review of literature clearly indicates that the load carrying capacity of the composite slab is mainly affected by the interfacial shear interaction. The interfacial shear depends on many parameters, such as height, shape, orientation of the embossment pattern, and the mechanical shear connector. The parameters that affect the shear-bond capacity need a series of tests and linear regression analysis. The composite strength of composite deck varies with the capacity of horizontal shear transfer between the concrete slab and steel deck. It is found that the interface shear strength depends on the embossment patterns. These embossments patterns are unique in character which requires separate performance evaluation tests even for a slight change in the geometry.

In addition to the interfacial shear forces, the flexure also leads to vertical separation between the steel and the concrete. Resistance to vertical separation needs to be examined with these embossments. The production of dimples and embossments leads to a cost escalation of about 25 to 50 percent of the decking profile cost. Any change in the existing embossments again needs a series of testing and this makes the analysis of composite deck slab complex.

The studs fastened at the deck end for the anchorage perform better. But the shear-bond slip at the sheet-concrete interface governs the strength rather than the strength of end constraints. Welding studs or rods over the deck top flange 
can modify the shear-bond failure of composite slabs. But the welding of shear connectors is not a successful concept. The metal decking sheet is generally about $1 \mathrm{~mm}$ thick, and welding the studs on the metal surface weakens the metal sheet strength. The welding heat induces voids, cracks, and erupts out of molten metal which weaken the bond strength of joints. The welding of studs also considerably escalates the cost [9-11]. The screw type shear studs were found successful then the welded studs for the end anchorage between steel beam and concrete with higher plasticization. In view of the forementioned, it is necessary to obtain shear interaction without the cost escalation and without weakening the metal strength by welding.

In addition to the performance, the analysis and design of composite deck slab behaviour is complex due to the partial interaction between metal deck and concrete. Full composite interaction between metal deck and concrete makes the design procedure of composite deck system become simple and straight forward. Suitable mechanism is the necessity of present days to overcome the above difficulties and deficiencies. Composite slab with a full shear interaction can reduce the rigid procedures. The bolted studs seem to be a better option for the interface mechanism with higher plasticity and overall ductility. These studs should mandatorily be efficient to control slip and uplifting of concrete. This enlightened us to develop a mechanism to control slip and uplifting forces for effective interface. In the present paper, three types of shear transferring mechanisms are developed using mechanical shear connectors. The bolts and/or steel rods are fastened in the metal deck to control the debonding forces at the interface. The holes are created to affix the shear connectors at the appropriate locations of web and flange of the metal deck. The metal sheet having enough resistance against the metal tearing and the process of creating the holes do not affect the metal strength. Series of experimental investigations are carried out to evaluate the efficiency of these three shear connector mechanisms on better interface strength.

\section{Development of Deck and Composite Slab}

The shear connectors present in the composite deck slabs effectively transfer interfacial shear. The embossment pattern type shear connectors have their own difficulties in terms of uniqueness in character and their cost escalation for production. The mechanical shear connectors are simple to implement with a negligible cost escalation. These mechanical shear connectors are fastened with metal deck by welding, bolting, or screwing into the surface. The welding of studs with deck sheet is categorical due to its tough measures. The present investigation is carried out experimentally with mechanical shear connectors without welding. One mm thick mild steel sheets are used in this investigation. The plain steel sheets are pressed into trough shape with a size measuring $750 \mathrm{~mm}$ width, $1830 \mathrm{~mm}$ length, and $75 \mathrm{~mm}$ depth, and they are developed as shown in Figure 2.

The metal deck profile was fabricated with a press breaker machine. It is a high precision machine which presses, bends, folds, and accurately forms the deck profile. The holes are

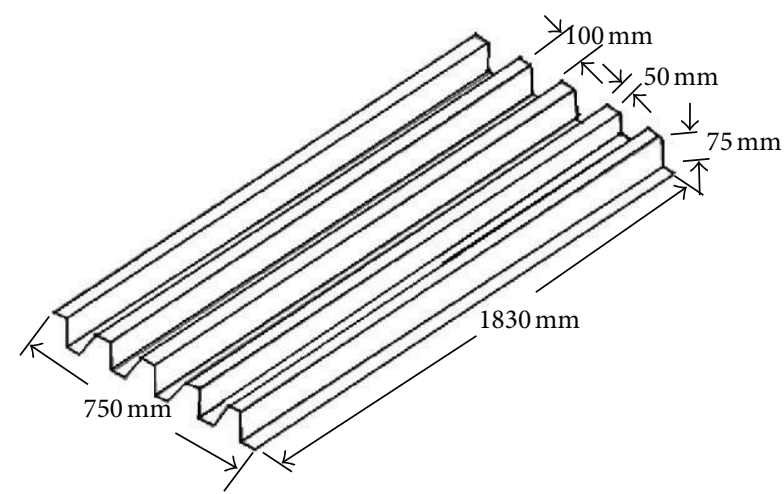

FIgURE 2: Schematic view of metal deck sheet.

produced by punching with relevant equipment fitted with these press breaker machines. The holes in the deck are formed with a minimum edge distance of $75 \mathrm{~mm}$ between the hole and sheet edge accurately. The centre to centre distance between the individual holes in a line along the length of sheet is kept as $300 \mathrm{~mm}$. The holes are formed at the appropriate locations of the deck flange and web. The shear connectors are positioned through these holes. Three types of shear connector schemes are derived based on the position of shear connector assemblies.

Out of these three shear connector schemes, the first type is proposed with fastening of $8 \mathrm{~mm}$ diameter bolts with $100 \mathrm{~mm}$ length at $300 \mathrm{~mm}$ center to center distance on the web of trough profile. These bolts are placed perpendicular to the web in a staggered manner in the opposite webs to simulate equivalent dove tail action. These bolts are designed to transfer the bond separation forces in terms of longitudinal interfacial shear forces and the uplifting force of slab efficiently as shown in Figures 3(a) and 3(b). The bolts are fixed by tightening the nut and this type of shear connector mechanism is designated as schemel.

The second shear connector scheme is proposed with higher shear strength in both transverse shear and uplift force, separately. In this shear connector mechanism, the bolts are placed at the top flange of deck for the transverse shear force, and $8 \mathrm{~mm}$ rod is inserted through the hole which is created at the middle height of deck web for uplifting force as shown in Figure 4(a). The schematic view of scheme 2 shear connector scheme is shown in Figure 4(b). The second shear connector mechanism is purposefully planned with higher shear capacity to achieve full shear interaction and it is designated as scheme 2 shear connector scheme.

In the third shear connector scheme, $10 \mathrm{~mm}$ steel rod is affixed to control both the transverse shear force and the uplifting force. In this shear connector mechanism, $10 \mathrm{~mm}$ high strength deformed bars are inserted through the holes created at the deck web center of steel deck in the direction perpendicular to the primarily reinforced direction as shown in Figure 5(a), and the schematic view of scheme 3 is shown in Figure 5(b). The steel rods are placed at $150 \mathrm{~mm}$ from the web edge and $300 \mathrm{~mm}$ distance between the adjacent rods.

The construction of composite system requires minimum reinforcement over the deck for accounting shrinkage and 


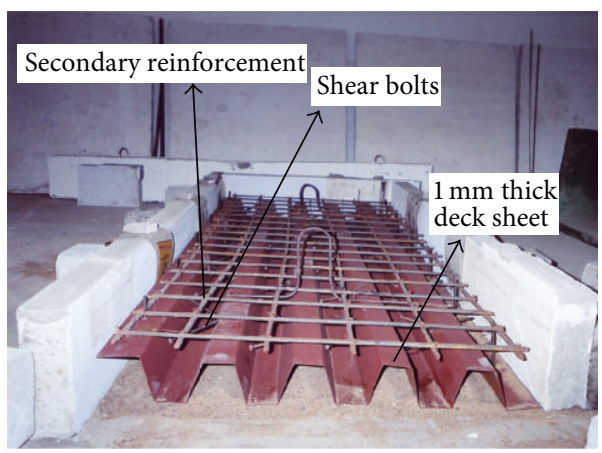

(a)

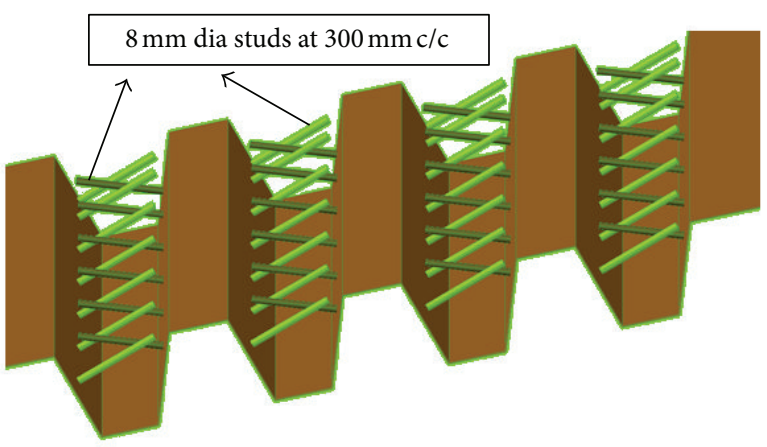

(b)

FIGURE 3: (a) Trough deck with schemel mechanical shear connector and (b) schematic view of metal deck with schemel shear connector.

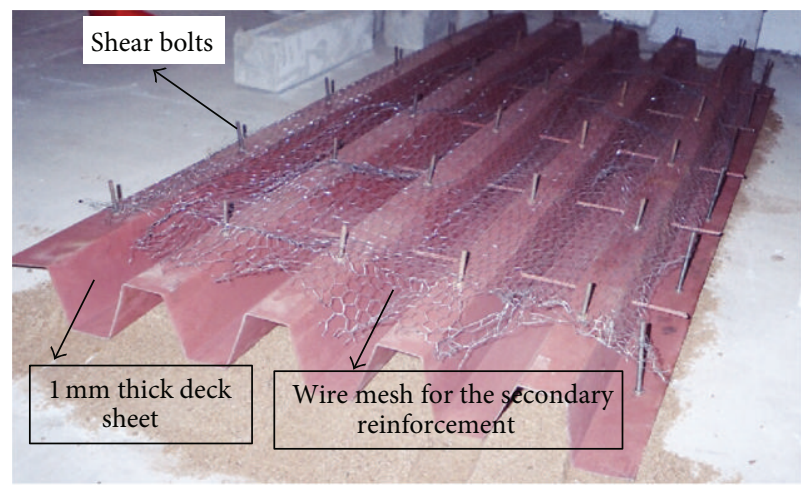

(a)

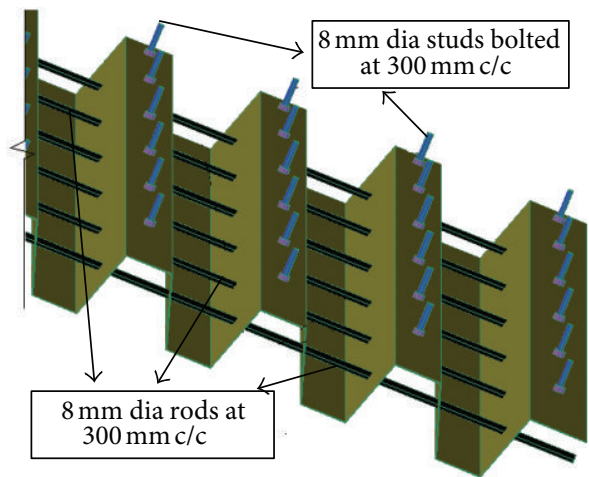

(b)

Figure 4: (a) Trough deck with scheme2 mechanical shear connector and (b) schematic view of metal deck with scheme2 shear connector.

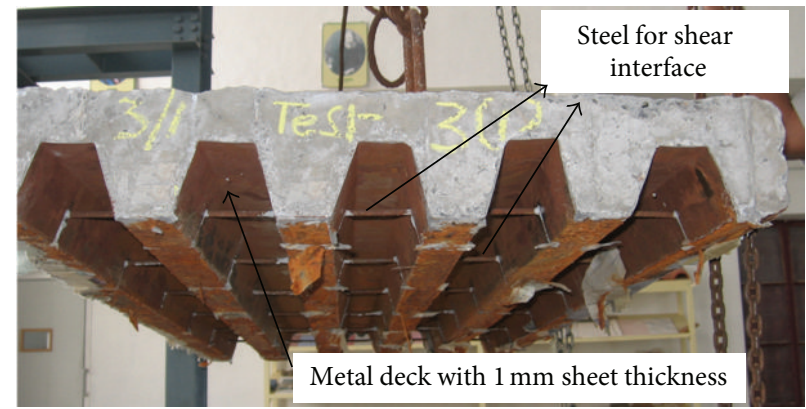

(a)

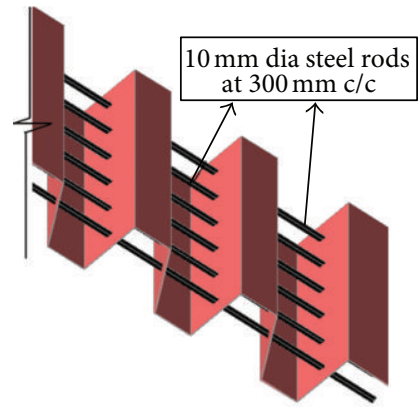

(b)

FIgURE 5: (a) Trough deck with scheme3 mechanical shear connector and (b) schematic view of metal deck with scheme3 shear connector.

temperature effects. These secondary reinforcements were also utilized to control the negative moments. Generally about 6 to $8 \mathrm{~mm}$ diameter reinforcements, welded meshes, or the synthetic meshes were used for this purpose. When the steel reinforcement is used as a secondary reinforcement, it is connected with a metal sheet by welding to enhance the control over the interface separation as shown in Figure 6. The secondary reinforcement provided over the top of the deck improves the load carrying strength of composite slab about 10 percent. Mounting reinforcing bars over the deck in both directions help minimize the cracking of compositedeck slabs. The bars also help in reducing the slab curling and the local damage of deck profile during concreting.

In view of Figures 4 and 5, the proposal of implementing full shear interaction particularly in scheme 2 and scheme 3 shear connectors, the strength and stiffness of metal deck are improved and they withstand the local damage during concreting. To economize the composite deck, this paper also made an attempt to address the issue of using light weight chicken mesh for the secondary reinforcements instead of 


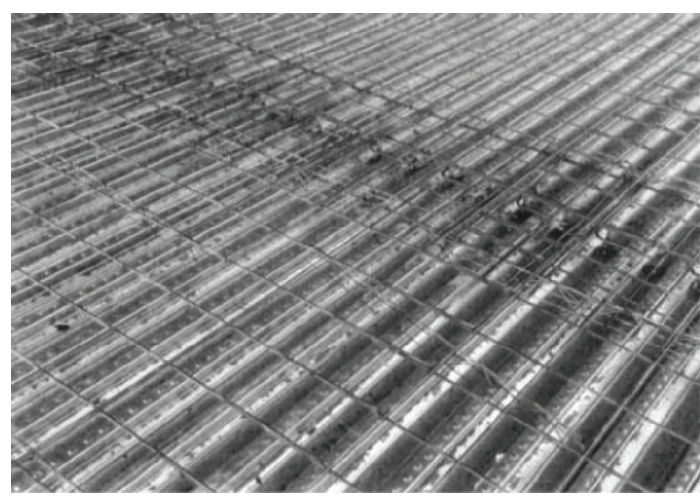

FIGURE 6: Typical view of secondary steel reinforcements [12].

steel reinforcement mat at the top of the composite slab. The use of chicken mesh is very simple to handle and practise due to its flexible steel wires. The chicken mesh can efficiently control the temperature and shrinkage stresses. Three composite slab specimens are cast for each shear connector scheme. Out of three composite slab specimens, one slab was examined with $8 \mathrm{~mm}$ diameter bar and the other two slabs are with chicken mesh for secondary reinforcements. The selection of $8 \mathrm{~mm}$ steel reinforcement is an arbitrary choice mainly to evolve the possibilities in strength reduction due to chicken mesh. The concrete is placed over the steel deck and the overall depth of $120 \mathrm{~mm}$ is precisely maintained in all slab castings. To assess the performance of composite slabs with mechanical shear connecters, testing of composite slabs without mechanical shear connecter is carried out. Since the reinforced concrete is engaged in the major portion of construction industry, the composite deck slab performance is also compared with the test results of reinforced concrete slabs for better perceptive. The M25 concrete of mix proportion $1: 1.5: 3: 4.8$ with 28 th day average compressive strength of $33.25 \mathrm{~N} / \mathrm{mm}^{2}$ is used for concreting. The trough deck profile was produced from the mild steel sheet of $1 \mathrm{~mm}$ thickness with modulus elasticity of $2.1 *$ $10^{5} \mathrm{~N} / \mathrm{mm}^{2}$ and Poisson's ratio of 0.3 . The readily available steel studs and rods are used as shear connectors. Modulus elasticity of steel studs and steel rods is $2.1 * 10^{5} \mathrm{~N} / \mathrm{mm}^{2}$ and Poisson's ratio is 0.3 .

\section{Load Setup and Testing Method}

The composite slabs are prepared to be tested under twopoint loading condition. The schematic view of the experimental setup and the photographs of the hinge and roller supports are shown in Figure 7. Two mild steel rods of $50 \mathrm{~mm}$ diameter are placed over the slab to apply a perfect line load. The rods are placed at a distance of $\mathrm{L} / 4$ from the supports. A standard I section ISMB 200 is placed over the rods in the transverse direction. A 30 ton hydraulic jack is fixed in the loading frame for applying load. The load is measured with a proving ring which is kept between the hydraulic jack and the ISMB 200 section. The dial gauges are used to measure the mid span deflection and end slip. The mid span deflection and the end slip are noted down at specific load intervals. The test series is started with testing of composite slab without any mechanical shear connector. The two-point load is applied on slabs and corresponding deflections are observed. The steel deck and concrete are separated due to the lack of bond between the steel deck and concrete as shown in Figure 8 . The load carrying capacity and stiffness are reduced due to the loss of composite action between concrete and metal deck. The composite slab without shear interaction carring a maximum average load at about $65 \mathrm{kN}$ is observed from the test. The metal deck and concrete completely debonded from each other and that makes the two parts act separately. The loss of composite action is evidenced from the metal sheet buckling at the web top. The results showed the necessity of efficient interface bonding between steel and concrete of composite deck system. The mechanical shear studs and rods are necessary to modify the performance of composite system by controlling the slip and uplifting forces. Three shear connector schemes are implemented to control the interface behaviour.

The composite slabs with different mechanical shear connector schemes are tested to failure. The load is increased and corresponding deflections at three points along the center line of slab are noted. Until the load reaches ultimum, it is applied as a load control increment and after that the load is altered with a displacement control, in which the jack head movement is controlled with the deflection increment in the central deflection. During the test, no sudden drop in load is observed up to ultimate load. In the entire testing of composite slab with mechanical shear connectors, no slip was observed. Also it is found that the secondary reinforcement in the form of chicken mesh or the $8 \mathrm{~mm}$ rod is not much affecting the performance of composite deck slabs. The composite slabs are performed in a ductile manner. The ultimate load carrying capacity of the composite slab with mechanical shear connector increased considerably and attained about 100 to $120 \mathrm{kN}$. The failure patterns of composite slab with mechanical shear connector are showing in Figure 9. The composite slab initially shown several microcracks and few cracks is widened after ultimate failure without showing any slip at the end.

From the experimental investigations, all three types of mechanical shear connectors performed well and no slip nor uplifting between concrete and deck sheet was observed. The composite slabs with shear connectors exhibited full shear interaction with remarkable increase in the load carrying capacity.

\section{Results and Discussion}

Three numbers of composite slabs without any shear connectors (NSC) are tested under two-point loads. The load is increased in steps, and corresponding center span deflections of slabs are measured up to peak. Furthermore after reaching the peak load, the load is altered for the increase of deflection and corresponding load is observed. The slab exhibited merely a linear behaviour till the load reaches about $38 \mathrm{kN}$ and suddenly the load dropped to about $30 \mathrm{kN}$. 


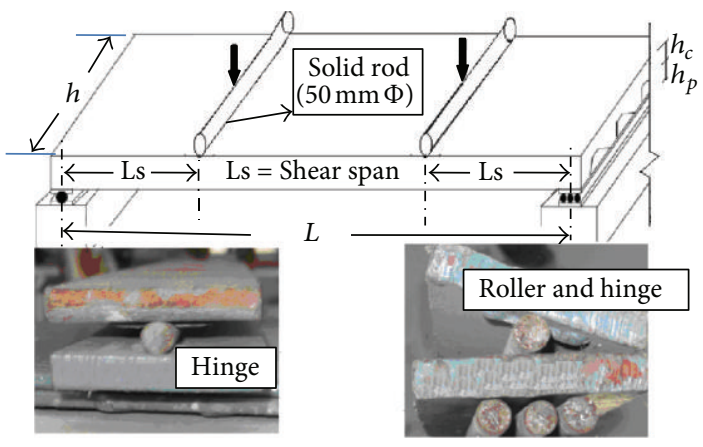

(a)

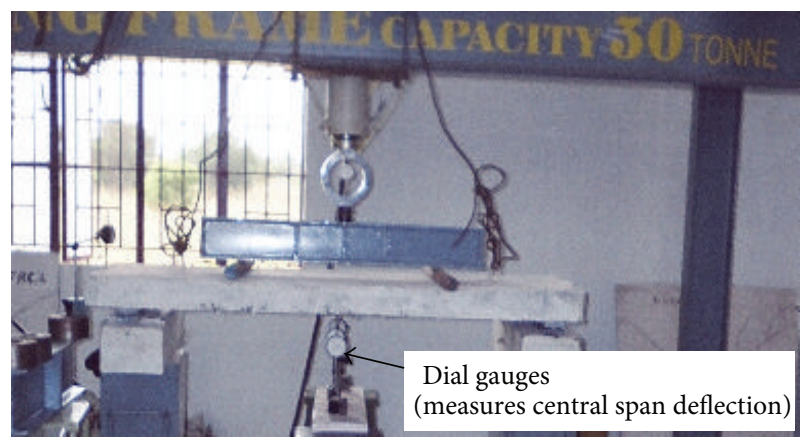

(b)

FIgURE 7: Typical view of loading setup and support details.

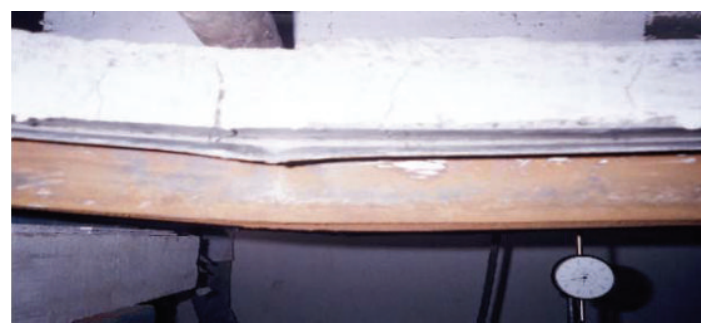

Figure 8: Debonding and separation failure of composite slab without shear connector.

The center span deflection is increased abruptly with a visible slip of about $2 \mathrm{~mm}$ at end. Further the load increased with increase of center deflection and end slip simultaneously. The composite slabs completely lost their composite action and developed an opening between concrete and metal deck. The load deflection performance of composite slabs without shear connector is presented in Figure 10 with an identity designation NSC.

Three composite slabs without the mechanical shear connectors behaved in an identical pattern with slight variation of results. The ultimate failure load observed from the experimental study is about $65 \mathrm{kN}$. At the failure of specimen, about $13 \mathrm{~mm}$ visible end slip and separation of concrete and steel deck are observed. The slip causes complete separation and it emphasizes to implement a supplementary technique. A reinforced concrete slab with $120 \mathrm{~mm}$ depth and reinforced with $10 \mathrm{~mm}$ steel rod at both directions is tested for a vital comparison. The average ultimate failure load of about $71 \mathrm{kN}$ is observed from the experimental study. The load carrying capacity of reinforced concrete slab is about 15 percent more which shows the deficiency in composite slab without shear connector.

Three shear connector schemes are implemented to overcome the slip and uplifting. Three numbers of composite slabs with schemel shear connectors are tested under two point loads with a suitable load increment. The behaviour of slab is a comparable trend with any reinforced concrete design. The load drops after reaching the ultimate load at about $115 \mathrm{kN}$. After reaching load drop, the load is altered with an increase in deflection, and corresponding load in the proving ring is observed. The slab exhibited nonlinear behaviour with expected full shear interaction. The load deflection performance of composite slab with schemel shear connector is presented in Figure 11 with an identity designation t1CSLB.

Three composite slabs with schemel mechanical shear connectors behaved in a similar pattern. The secondary reinforcements for creep and shrinkage are examined with $8 \mathrm{~mm}$ steel rod and with chicken mesh. Both of the secondary reinforcements have exhibited similar behaviour with about 5 to 10 percent variation in strength. The chicken mesh shows impressive results for the secondary reinforcements instead of the conventional steel rods at nonnegative bending moment. The effect of chicken mesh at negative moment region is not covered in the present investigation. The composite slab with schemel shear connector exhibited complete interaction between steel and concrete surfaces. The full shear interaction improved strength, stiffness, and ductility of composite slab. The slabs failed in flexure and no slabs failed in interface separation and slip. The load carrying capacity improved about 75 percent of additional load compared to the composite slab without shear interaction. The failure pattern is gradually descening after the peak load and replicated under reinforced concrete behaviour.

The scheme2 shear connectors are examined for their efficiency and the same test procedures were followed as earlier. The slab exhibited nonlinear behaviour with full shear interaction similar to that of schemel shear connector. The load deflection behaviour of composite slabs with scheme2 shear connector is plotted and displayed in Figure 12 with an identity designation $\mathrm{t} 2 \mathrm{CSLB}$.

Three composite slabs with scheme 2 mechanical shear connectors are performed in an identical pattern. The ultimate failure load at about $120 \mathrm{kN}$ is observed from the experimental study. The performance of composite slab with scheme2 shear connector is not much affected with light weight chicken mesh and steel rod for the secondary reinforcement. The failure pattern of composite slab with scheme 2 shear connectors has shown similar ductile performance like schemel shear connector. The slab failed in flexure and the scheme2 shear connectors offered good resistance against the interface bond failure. Shear connector schemes, schemel and scheme2, offered resistance against the longitudinal shear as well as the uplift debonding forces. 


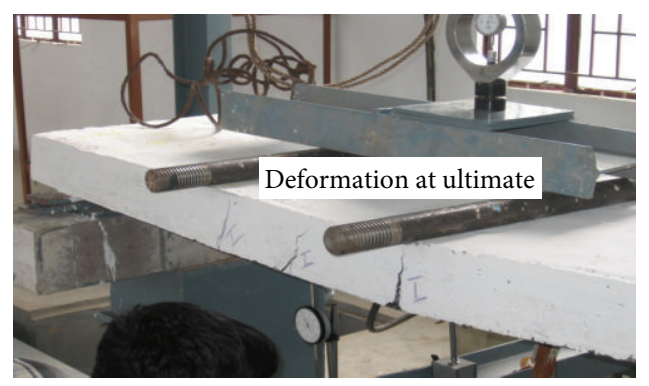

(a)

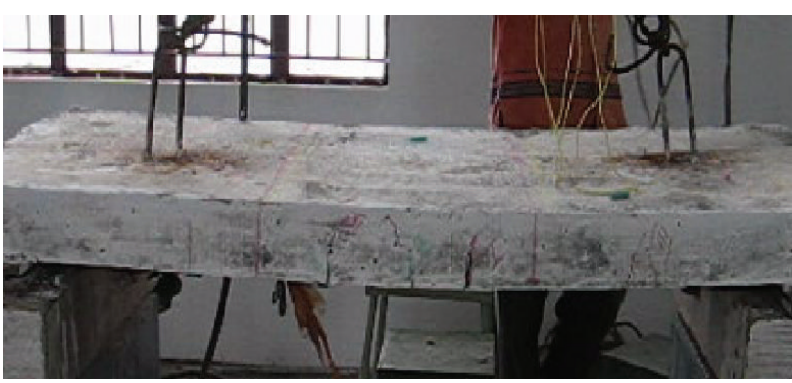

(b)

FIGURE 9: Typical failure patterns of composite slab with shear connector.

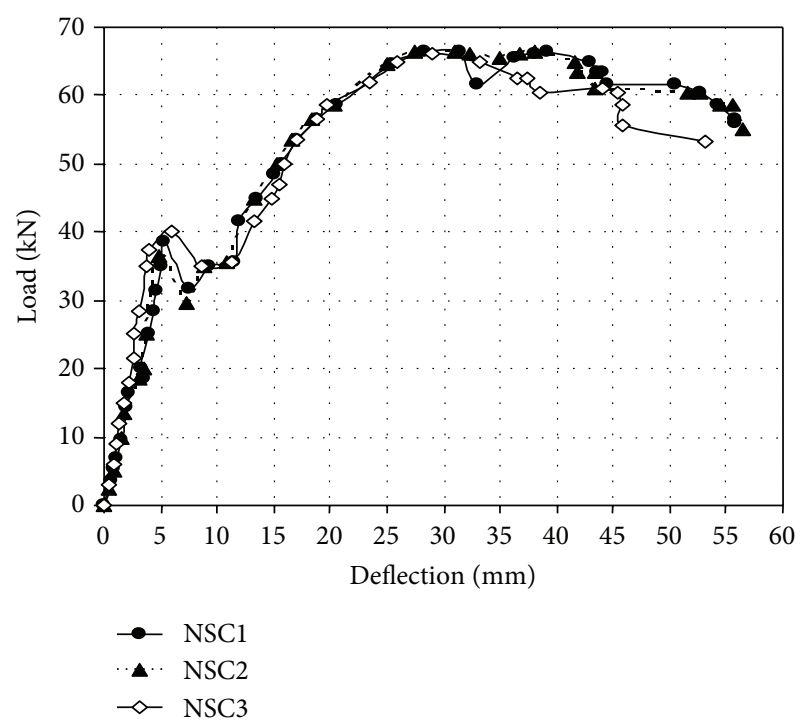

FIGURE 10: Failure pattern of composite slab without shear connector.

Three numbers of composite slabs with scheme3 shear connectors are investigated. In scheme3, continuous steel rod is inserted at the center of deck to control the slip and separation of surfaces. This experimental study aimed to assess the efficiency of the inserted rod for the transfer of both longitudinal and uplifting forces. The load is increased in steps with suitable load interval, and the center span deflections of composite slab are measured. The drop in the load is observed at about $115 \mathrm{kN}$. After reaching load drop, the load is altered for an increase of deflection, and corresponding load in the proving ring is observed. The slab exhibited nonlinear behaviour with full shear interaction similar to that of schemel and scheme2 shear connectors. The load deflection performance of composite slab with scheme3 shear connector is plotted as shown in Figure 13 with an identity designation t3CSLB. Three composite slabs with scheme 3 mechanical shear connectors have performed well.

The composite slab with scheme3 shear connectors with chicken mesh as secondary reinforcement has performed well. The failure pattern of composite slab with scheme3 shear connectors has shown similar ductile performance to

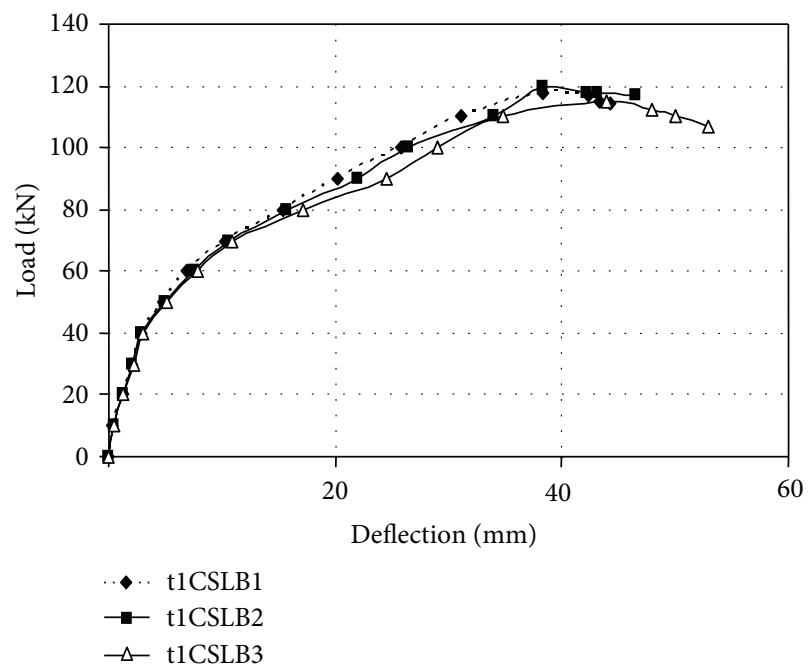

FIGURE 11: Load deflection plot for composite slab with scheme1 connector.

that of schemel and scheme 2 shear connector schemes. The performance composite slab with scheme3 shear connector scheme is comparable with the performance of slab with scheme2 shear connector. The scheme3 shear connector seems to be more economical when compared to the other two shear connector schemes. The three shear connector schemes exhibited full shear interaction, and the bond slip comparison is shown in Figure 14 which confirms the control over the slip. The load slip behaviour of composite slabs clearly indicates the importance of mechanical shear connectors.

The performances of different slabs are given in Table 1. The load deflection performances of different types of slabs are compared in Figure 15.

The defective performance of composite slab without shear connector is modified by adding the shear connectors. The slab with all the three schemes of shear connectors showed a uniform behaviour with a negligible slip and exhibited a full shear interaction. The slip measured in the composite slab with shear connectors is very meager and negligible. All three types of shear connectors performed well in controlling the bond slip between concrete and steel deck. 


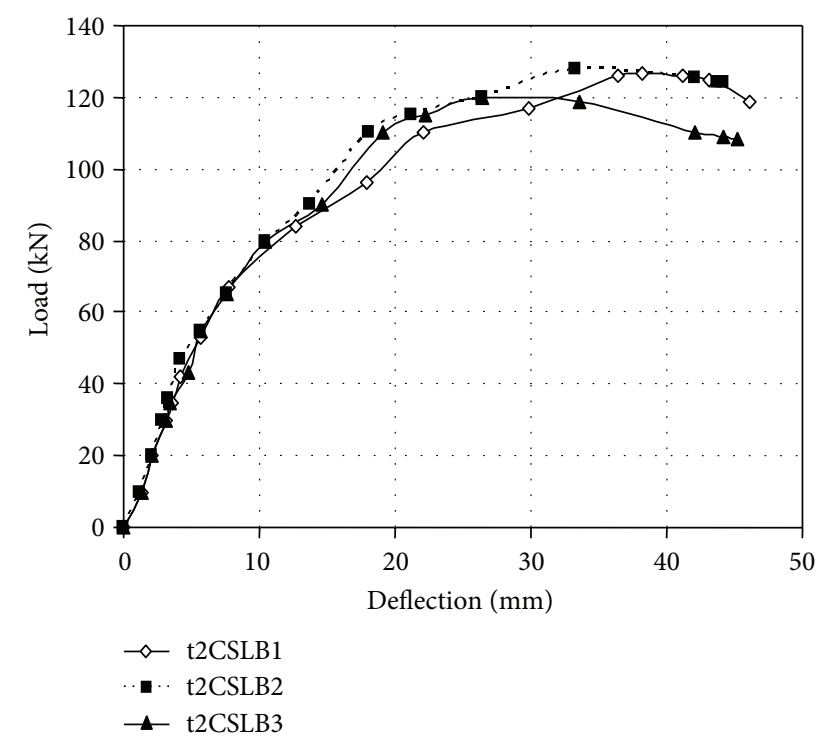

FIGURE 12: Load deflection plot for composite slab with scheme2 connector.

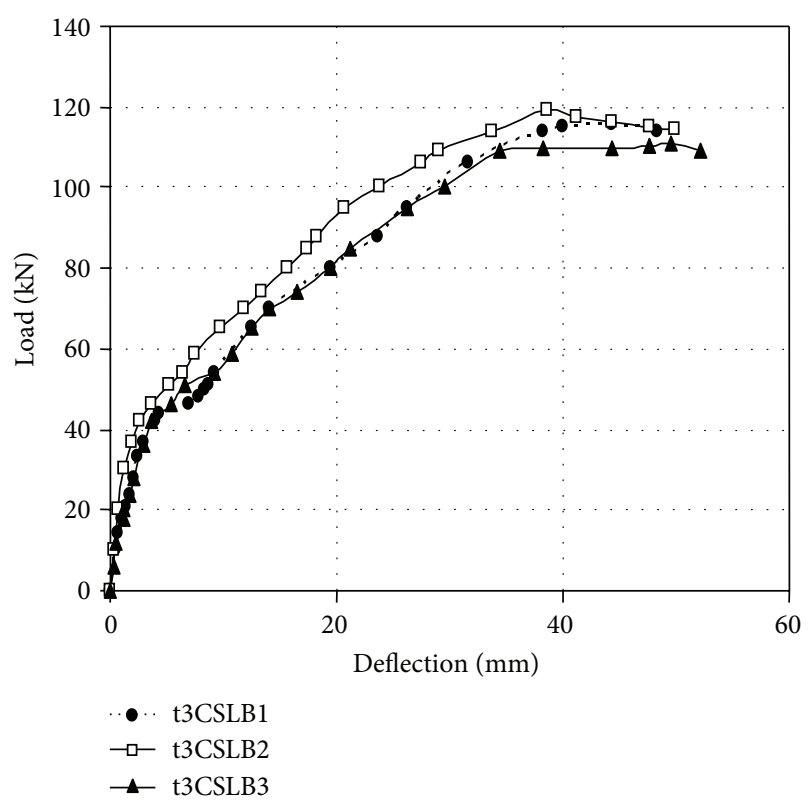

FIGURE 13: Load deflection plot for composite slab with scheme3 connector.

The ultimate load carrying capacity of composite slab is increased due to the presence of mechanical shear connector. The schemel, scheme2, and scheme3 shear connector schemes exhibit better performance in terms of the increase in stiffness, strength with deflection reduction compared to reinforced concrete slab and composite slab without shear connector. Composite slabs with these three types of mechanical connectors reached the ultimate load about $115 \mathrm{kN}$. The stiffness of metal deck in primary reinforcement direction is high and it has negligible stiffness in the other direction. The insertion of steel rod at the middle of the deck web in scheme2
TABLE 1: Load deflection results of different composite slabs.

\begin{tabular}{cccccccccc}
\hline \multicolumn{2}{c}{ RCSLB1 } & \multicolumn{2}{c}{ NCSLB1 } & \multicolumn{2}{c}{ t1CSLB2 } & \multicolumn{2}{c}{ t2CSLB2 } & \multicolumn{2}{c}{ t3CSLB2 } \\
$\mathrm{L}$ & $\mathrm{D}$ & $\mathrm{L}$ & $\mathrm{D}$ & $\mathrm{L}$ & $\mathrm{D}$ & $\mathrm{L}$ & $\mathrm{D}$ & $\mathrm{L}$ & $\mathrm{D}$ \\
\hline 0 & 0 & 0 & 0 & 0 & 0 & 0 & 0 & 0 & 0 \\
1 & 0.17 & 3.5 & 0.58 & 5 & 0.2 & 5 & 0.28 & 10 & 0.32 \\
4 & 0.55 & 7 & 1.08 & 10 & 0.4 & 10 & 0.6 & 20 & 0.68 \\
6 & 0.74 & 9.5 & 1.56 & 15 & 0.71 & 15 & 0.79 & 30 & 1.24 \\
10 & 1.19 & 16.5 & 2.25 & 20 & 1.24 & 20 & 1.3 & 37 & 1.98 \\
12 & 1.64 & 20 & 3.42 & 25 & 1.65 & 25 & 1.7 & 42 & 2.68 \\
16 & 2.08 & 28.5 & 4.45 & 30 & 2.04 & 30 & 2.1 & 46 & 3.64 \\
20 & 2.62 & 31.5 & 4.73 & 35 & 2.42 & 35 & 2.4 & 51 & 5.23 \\
25 & 3.48 & 35 & 5.05 & 40 & 2.86 & 40 & 2.85 & 54 & 6.52 \\
30 & 4.3 & 38.5 & 5.4 & 45 & 3.81 & 45 & 3.78 & 59 & 7.54 \\
35 & 5.62 & 31.67 & 7.52 & 50 & 4.86 & 50 & 4.84 & 65 & 9.67 \\
40 & 6.95 & 35 & 9.2 & 55 & 5.91 & 55 & 5.87 & 70 & 11.85 \\
45 & 8.15 & 35.5 & 11.62 & 60 & 6.95 & 60 & 6.87 & 74 & 13.35 \\
50 & 9.37 & 45 & 13.6 & 65 & 8.38 & 65 & 8.04 & 80 & 15.68 \\
55 & 10.58 & 48.5 & 15.0 & 70 & 10.2 & 70 & 9.51 & 85 & 17.46 \\
60 & 11.72 & 53.5 & 17.1 & 75 & 12.75 & 75 & 11.43 & 88 & 18.21 \\
65 & 14.23 & 58.5 & 20.65 & 80 & 15.4 & 80 & 13.42 & 95 & 20.73 \\
67 & 17.65 & 66.5 & 28.25 & 90 & 20.26 & 90 & 15.96 & 100 & 23.82 \\
68 & 21.97 & 66.5 & 31.35 & 100 & 25.82 & 100 & 19.43 & 106 & 27.45 \\
69 & 22.78 & 61.5 & 33 & 110 & 31.1 & 110 & 24.78 & 109 & 29.12 \\
72 & 24.17 & 65.5 & 36.32 & 120 & 38.4 & 127 & 35 & 114 & 33.67 \\
74 & 28.53 & 66.5 & 39.21 & 117 & 42.3 & 122.5 & 41 & 119 & 38.65 \\
69 & 32.46 & 65 & 43.02 & 115 & 43.32 & 120.5 & 43 & 115 & 47.64 \\
63 & 34.26 & 61.5 & 50.53 & 114 & 44.27 & 119 & 45 & 114.5 & 49.87 \\
\hline
\end{tabular}

"L" represents load in $\mathrm{kN}$ and " $\mathrm{D}$ " represents center span deflection in $\mathrm{mm}$.

and scheme3 shear connector schemes ties and integrates the metal deck. The new method of integration improves the strength and stiffness of metal deck in both directions. The increase in strength and stiffness of decking profile sheet is a positive sign during placing concrete which can reduce formworks and props. The scheme 3 shear connector scheme also has a scope in two-way deck slab application with a minimum cost which is schematically shown in Figure 16.

The energy absorption of different slabs is derived from the load deflection plots to enrich evidence for the efficiency of composite slab with shear connectors. The energy absorption is calculated up to the ultimate load by calculating the area under the load deflection curve. The composite deck slab without mechanical shear connector showed very low energy absorption of about $1800 \mathrm{Nm}$. The energy absorption of reinforced concrete slab is found about $2035 \mathrm{Nm}$. The composite slab with mechanical shear connector absorbed energy about $3748 \mathrm{Nm}$.

The composite slabs without shear connectors seem to be inferior when compared to the reinforced concrete slab. The load carrying capacity of composite slab without shear connector is 15 percent below when compared to that of reinforced concrete slab which is modified with the addition of mechanical shear connectors. Addition of shear connectors converts the poor behaviour of composite slab to superior performance when compared to that of reinforced concrete 


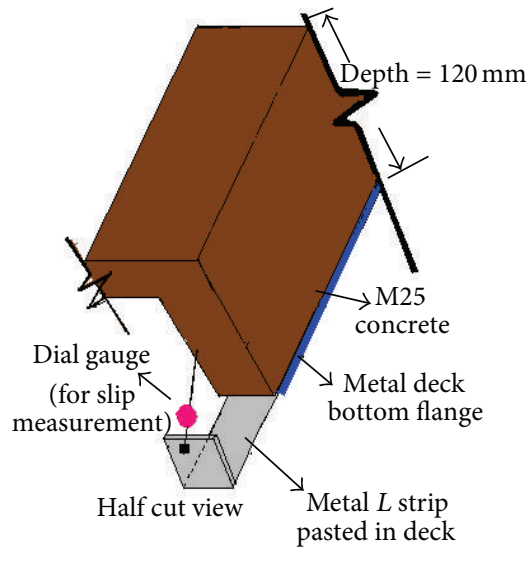

Setup for end slip measurement

(a)

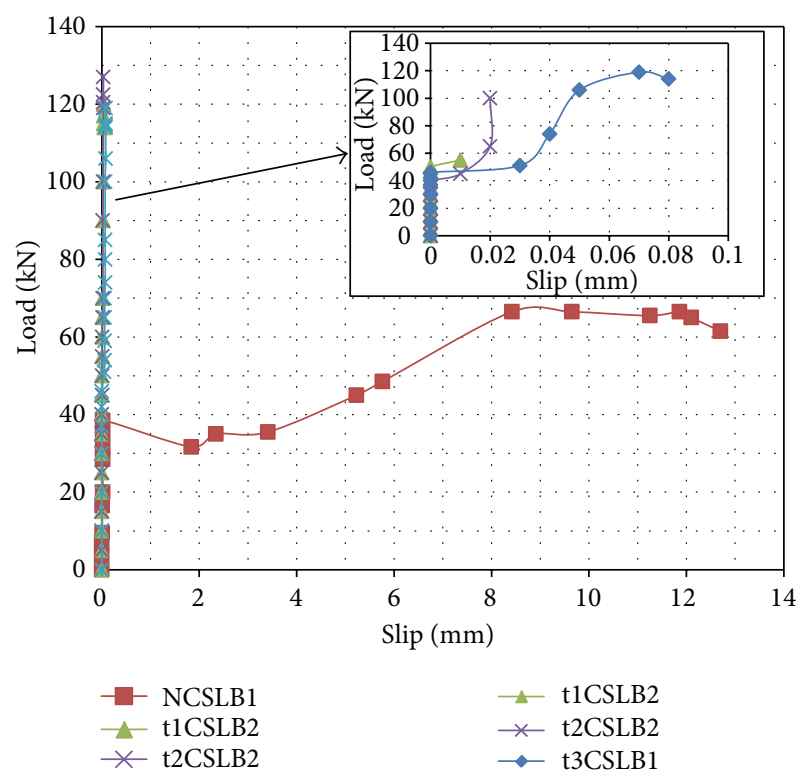

(b)

FIGURE 14: Load-slip comparison of different type of composite slabs.

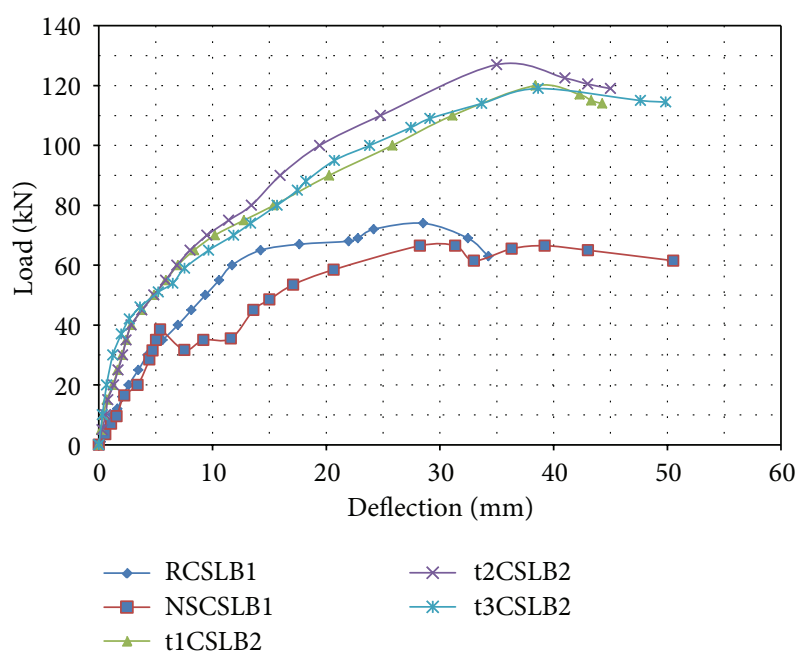

FiguRE 15: Load deflection comparisons for different type of slabs.

slabs. The composite slab with mechanical shear connector carried about 60 percent more load when compared to the reinforced concrete slab with the same depth. The load carrying capacity of composite slab without shear connector enhanced by about 110 percent with the addition of shear connectors with negligible cost escalation.

\section{Conclusion}

The slab constructed with stud bolts and shear rods showed a different behaviour when compared to that of the composite slab without shear connector. The full shear interaction is

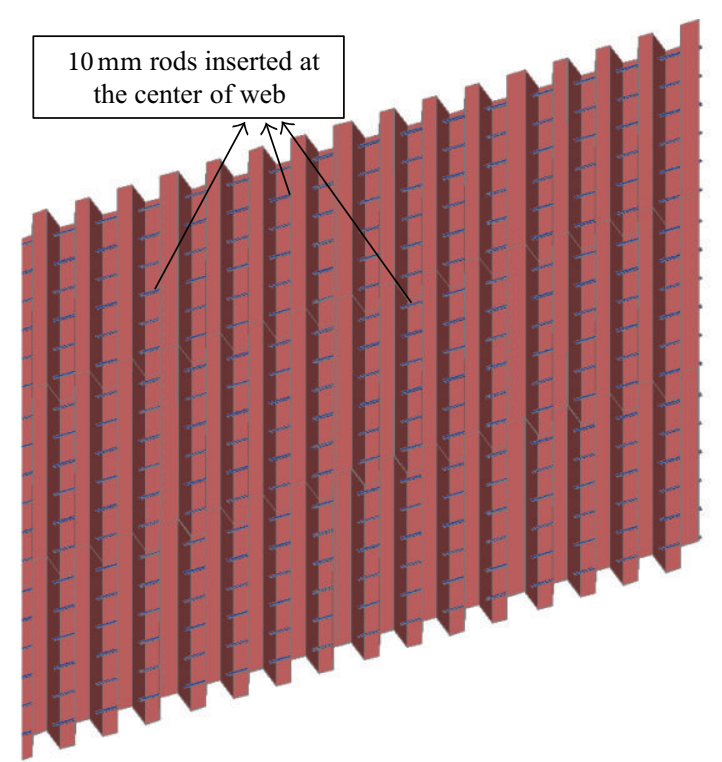

FIGURE 16: Schematic view of two-way deck slab with scheme3 connector.

achieved without drop in load before reaching the ultimate load, and a negligible slip is observed during the entire monotonic loading procedure. From the experimental investigations, the following was conduded.

(1) The composite slab without shear connectors slips and fails at the earlier load level. The insertion of shear connector modifies the brittle behaviour of the composite slab into ductile. 
(2) Three mechanical shear connector schemes develop full shear interaction and do not show any visible delamination and slip.

(3) The insertion of steel rods at the middle of the deck web in scheme 2 and scheme 3 shear connector schemes ties and integrates the metal deck. The integration improves the strength and stiffness of metal deck and reduces formworks and temporary supports.

(4) Steel rods present in the deck web can be efficiently tied and showcased for the two-way composite deck system.

(5) The inclusion of shear connector enhances the flexural capacity, stiffness, ductility, and energy absorption of composite deck system.

(6) The load carrying capacity is improved by about 110 percent when compared to that of the composite slab without mechanical shear connector with minimum/negligible cost escalation. The composite slab with mechanical shear connector carried about 60 percent additional load when compared to that of the reinforced concrete slab with same depth.

(7) The flexural capacity of composite deck slab with wire mesh is found competitive for shrinkage and temperature effects.

\section{Acknowledgment}

This paper is being published with the kind permission of Director of CSIR-SERC, Chennai.

\section{References}

[1] V. Marimuthu, S. Seetharaman, S. Arul Jayachandran, A. Chellappan, T. K. Bandyopadhyay, and D. Dutta, "Experimental studies on composite deck slabs to determine the shear-bond characteristic (m-k) values of the embossed profiled sheet," Journal of Constructional Steel Research, vol. 63, no. 6, pp. 791803, 2007.

[2] D. L. Mullett, Slim Floor Design and Construction, SCI-P-110, Steel Construction Institute Publication, Berkshire, UK, 1992.

[3] M. L. Porter, C. E. Ekberg Jr., L. F. Greimann, and H. A. Elleby, "Shear bond analysis of steel deck reinforced slabs," ASCE Journal of the Structural Division, vol. 102, no. 12, pp. 2255-2268, 1976.

[4] M. L. Porter and C. E. J. Ekberg, "Design recommendations for steel deck floor slabs," ASCE Journal of the Structural Division, vol. 103, no. 11, pp. 2121-2136, 1976.

[5] S. S. Seleim and R. M. Schuster, "Shear-Bond Resistance of Composite Deck-Slabs," Canadian Journal of Civil Engineering, vol. 12, no. 2, pp. 316-324, 1985.

[6] J. M. Calixto, A. C. Lavall, C. B. Melo, R. J. Pimenta, and R. C. Monteiro, "Behaviour and strength of composite slabs with ribbed decking," Journal of Constructional Steel Research, vol. 46, no. 1-3, pp. 211-212, 1998.

[7] A. I. Tenhovuori and M. V. Leskela, "Longitudinal shear resistance of composite slabs," Journal of Constructional Steel Research, vol. 46, no. 1-3, p. 228, 1998.
[8] S. Chen, "Load carrying capacity of composite slabs with various end constraints," Journal of Constructional Steel Research, vol. 59, no. 3, pp. 385-403, 2003.

[9] W. S. Easterling and C. S. Young, "Strength of composite slabs," Journal of Structural Engineering, vol. 118, no. 9, pp. 2370-2389, 1992.

[10] S. Aslanlar, A. Ogur, U. Ozsarac, E. Ilhan, and Z. Demir, "Effect of welding current on mechanical properties of galvanized chromided steel sheets in electrical resistance spot welding," Materials and Design, vol. 28, no. 1, pp. 2-7, 2007.

[11] J. R. Ubejd Mujagić, W. S. Easterling, and T. M. Murray, "Drilled standoff screws for shear connection in light composite steelconcrete trusses," Journal of Constructional Steel Research, vol. 63, no. 10, pp. 1404-1414, 2007.

[12] J. W. Rackham, G. H. Couchman, and S. J. Hicks, "Composite slabs and beams using steel decking: best practice for design and construction," MCRMA Technical Paper 13, SCI Publication, 2009. 

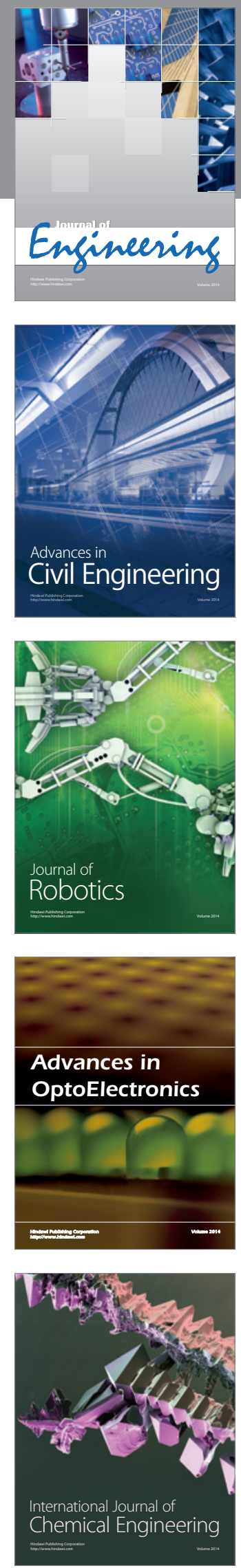

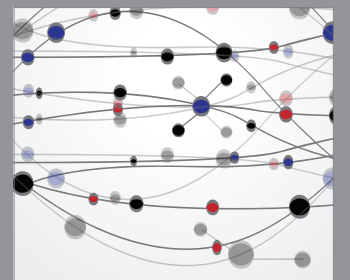

The Scientific World Journal
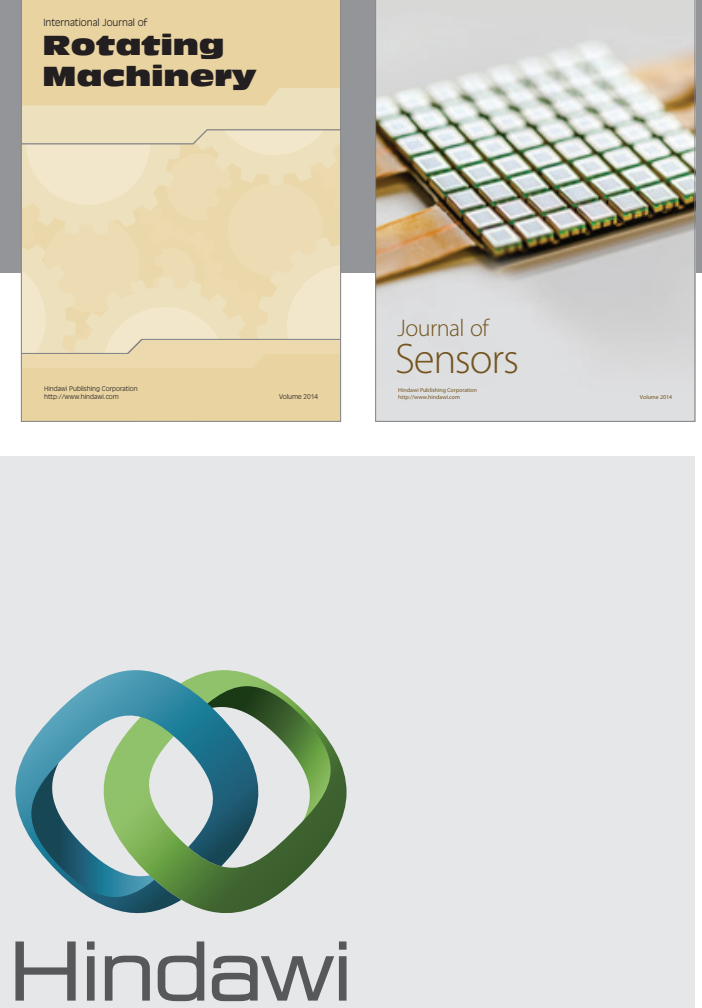

Submit your manuscripts at http://www.hindawi.com
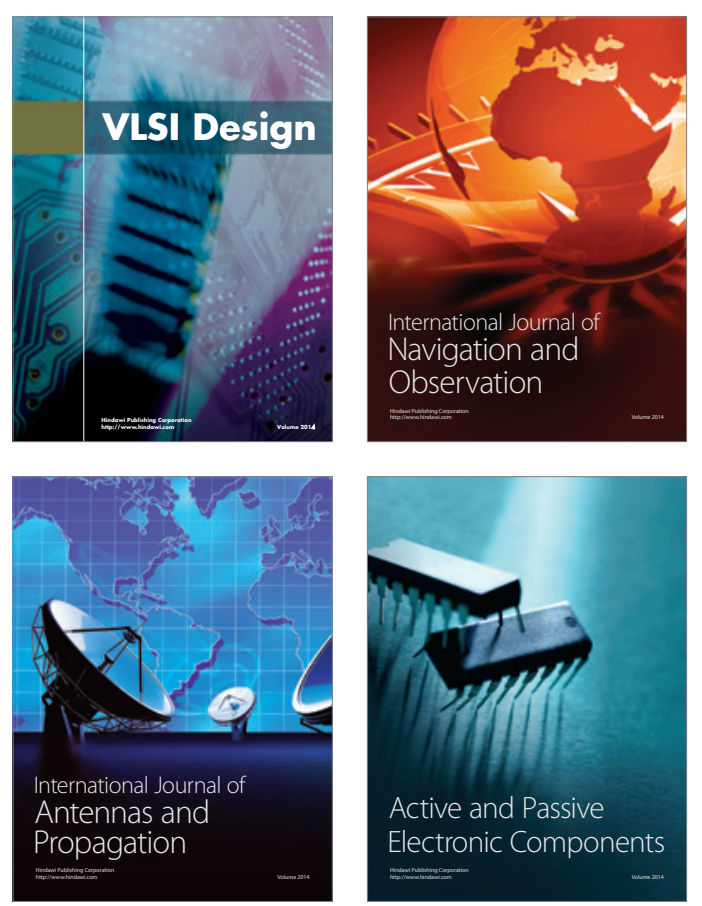
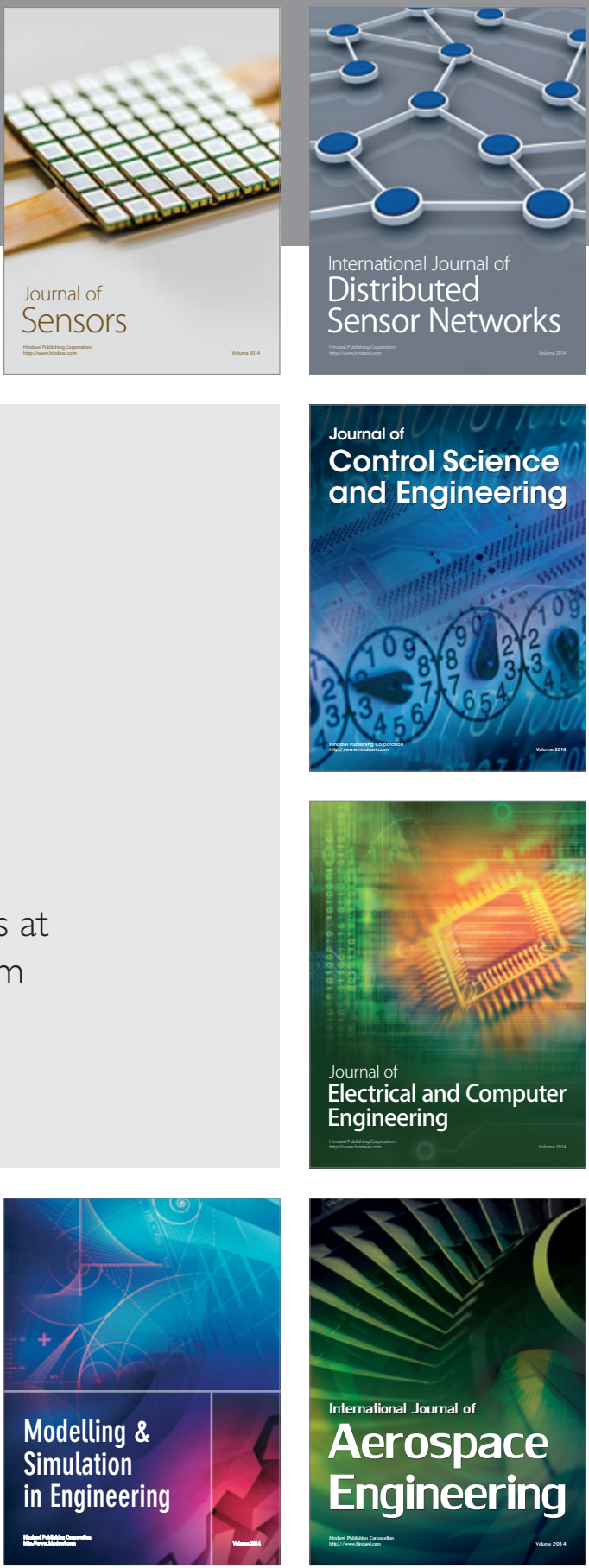

Journal of

Control Science

and Engineering
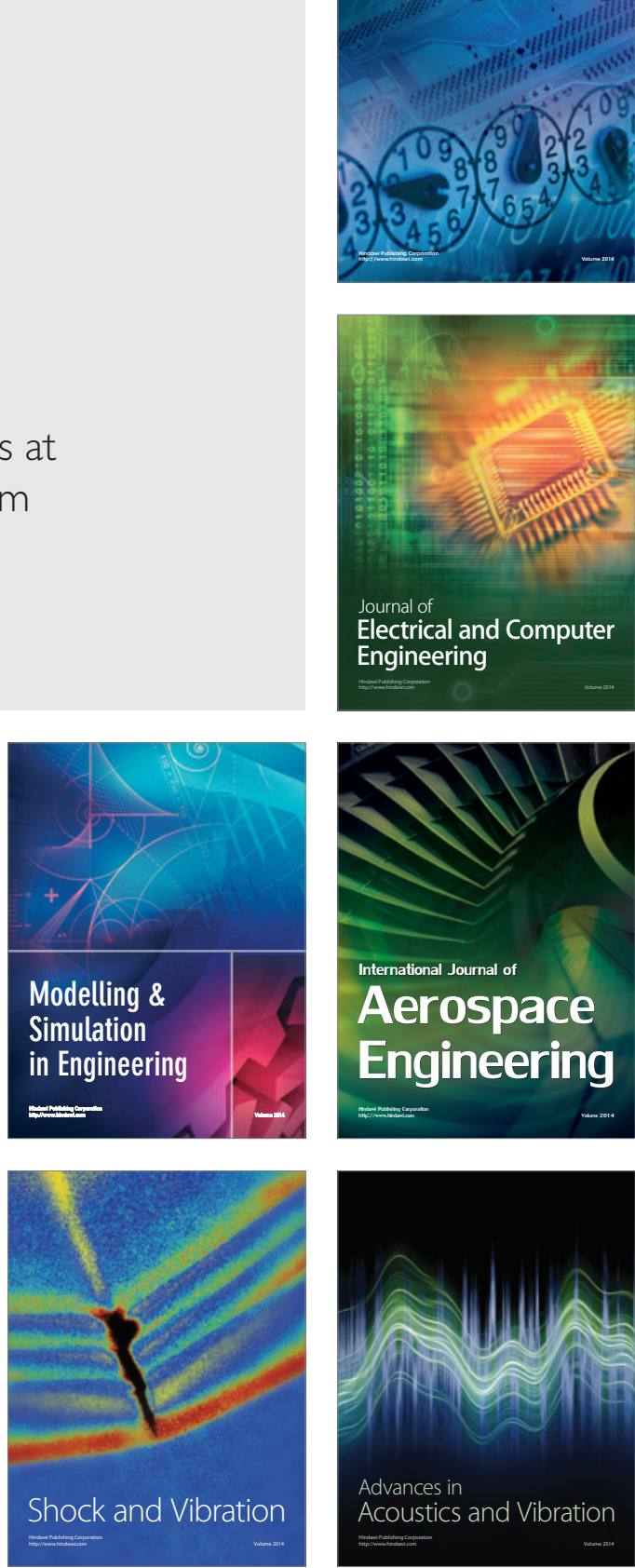